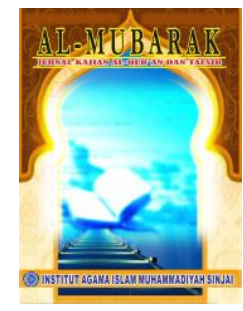

\title{
MUSYAWARAH DALAM PERSPEKTIF AL-QUR'AN
}

\author{
Firdaus \\ ${ }^{1}$ Institut Agama Islam Muhammadiyah Sinjai \\ E-mail:doktorfirdaus@gmail.com, Tlp:+628114188997
}

\begin{abstract}
Abstrak
Tulisan ini bertujuan untuk mendeskripsikan dan menganalisis makna-makna ayat AlQur'an terkait musyawarah, hal ini dilakukan mengingat konteks musyawarah merupakan satu bagian penting dalam kehidupan masyarakat muslim, sebagaimana Nabi Saw. telah menerapkan konsep musyawarah ini untuk memutuskan masalah dengan tepat. Metode penulisan ini adalah studi kepustakaan (library research) yakni menelaah sumber-sumber normatif yang dapat dijadikan sebagai sajian informatif dalam konteks kehidupan manusia (umat Islam) secara luas. Dengan demikian, makna daripada ayatayat musyawarah dalam Al-Qur'an betul-betul dapat diinterpretasi secara tepat dengan tidak melupakan konteks historis dimana ayat-ayat musyawarah tersebut diturunkan, sehingga yang dihasilkan adalah konsep yang tidak saja interpretatif tetapi implementatif. Pada akhirnya konsep musyawarah sebagaimana Al-Qur'an ketengahkan ini menjadi konsep yang dapat diterapkan secara global.
\end{abstract}

Kata Kunci: Musyawarah, Perspektifal-Qur'an

\section{Pendahuluan}

Sistem musyawarah sebagai bagian dari mekanisme pengambilan suatu keputusan, dalam sejarah Islam telah cukup lama dikenal dan dipraktekkan. Sejak masa awal pertumbuhan masyarakat Islam, tradisi musyawarah sudah mulai dipraktekkan dalam masyarakat. Nabi sendiri menganggap bahwa musyawarah merupakan salah satu sistem yang dapat digunakan untuk memutuskan suatu masalah dengan tepat. Karena itu, beliau selalu menempuh jalan tersebut dengan para sahabatnya ketika menghadapi berbagai persoalan, khususnya menyangkut kepentingan umum. Sebagai contoh, Nabi Saw bermusyawarah dengan para sahabatnya mengenai strategi Perang Badar dan Uhud, perjanjian Hudaibiyah, tawaran perang Badar dan perlakuan atas jenazah 'Abdullah bin Ubay ibn Salul (Al-Buthy, 1980: 214-215).

Setelah Nabi Saw meninggal, tradisi musyawarah tetap dipraktekkan oleh Khulafa' al-Rasyidun. Misalnya dalam masalah pengisian jabatan Kepala Negara selalu diselesaikan melalui musyawarah dengan cara yang berbeda-beda (Ahmad 


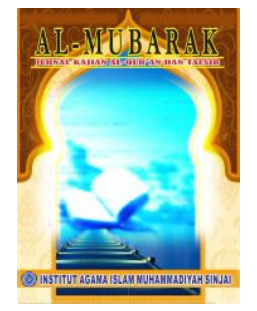

Al-MUBARAK

Jurnal Kajian Al-Quran \& Tafsir

Volume 4, No. 2, 2019

P-ISSN: 2548-7248

E-ISSN: 2715-5692

Homepage : http://journal.iaimsinjai.ac.id/indeks.php/al-mubarak

Syalabi, 1978: 380-381). Demikian pula dalam hal penentuan garis-garis kebijakan pemerintahan selalu ditempuh melalui jalan musyawarah (Jalal Syaraf dan Aly al-Mu'thy Muhammad, 1988: 21).

Oleh karena itu, Islam memandang musyawarah sebagai salah satu hal yang amat penting bagi kehidupan manusia, baik dalam kehidupan berbangsa dan bernegara, kehidupan berumah tangga dan lain-lainnya. Ini terbukti dari perhatian al-Qur'an yang menganjurkan umat Islam agar bermusyawarah dalam memecah berbagai persoalan yang mereka hadapi. Bahkan, musyawarah dapat mempersatukan sekelompok orang atau umat serta menghimpun atau mencari pendapat yang paling tepat.

Di samping itu, problema pokok yang akan diangkat berkisar pada apa hakikat dan bagaimana wujud musyawarah yang dapat dipahami dari ayat-ayat alQur'an. Lalu bagaimana pula prinsip-prinsip musyawarah menurut al-Qur'an. Masalah ini sangat penting untuk dibahas agar berbagai hal-hal yang berkaitan dengan musyawarah dalam al-Qur'an dapat dipahami secara komprehensif.

\section{Metode}

Penelitian ini adalah penelitian kepustakaan (library research). Objek kajian dalam penelitian ini adalah al-Qur'an dan tafsir. Sebagai penelitian al-Qur'an dan tafsir maka metode kajiannya adalah menggunakan metode kajian tematik. Adapun prosedur kajian tematik dalam penelitian ini dapat dilihat secara singkat pada alur berikut ini. Pertama, penelitian ini menetapkan topik musyawarah sebagai tema sentral. Kedua, mengidentifikasi ayat-ayat al-Qur' an terkait dengan musyawarah. Ketiga, mengetengahkan penafsiran ulama terhadap ayat-ayat musyawarah. Dalam hal ini, tidak lupa pula untuk menampilkan munasabah ayatnya, sebab nuzul jika ada, juga hadis Nabi sebagai penjelas terhadap keberadaan sebuah ayat. Keempat, melakukan analisa mendalam dan memberikan sebuah kesimpulan dari pemaknaan ayat musyawarah sehingga tema sentral terkait dengan musyawarah dalam perspektif al-Qur'an mendapatkan interpretasinya dengan tepat. 


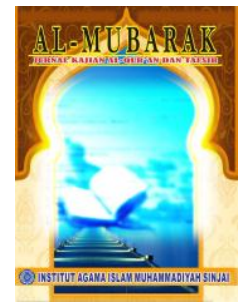

Al-MUBARAK

Jurmall Kajian Al-Quran \& Tafsir

Volume 4, No. 2, 2019

P-ISSN: 2548-7248

E-ISSN: 2715-5692

Homepage : http://journal.iaimsinjai.ac.id/indeks.php/al-mubarak

\section{Pembahasan}

\subsection{Pengertian Musyawarah}

Istilah musyawarah berasal dari bahasa Arab, yaitu مشاورة. Kata ini merupakan bentuk mashdar dari kata syaawara (شاور) yang artinya saling berembug. Adapun akar katanya berasal dari kata شور terdiri dari tiga huruf, yaitu syin, waw dan ra dengan makna dasar menampakkan dan menawarkan sesuatu serta mengambil sesuatu (Ibnu Faris, t.th.: 226). Dalam kamus Lisan al 'Arab, kata tersebut diartikan dengan mengambil madu dari sarangnya (Ibnu Manzhur, 2008: 160), terambil dari kalimat (شرت العسل) saya mengeluarkan madu dari wadahnya (M. Quraish Shihab, 1996: 469). Makna ini mempersamakan pendapat yang terbaik dengan madu karena pendapat yang baik dan paling tepat sangat bermanfaat bagi manusia, begitu pula dengan madu, dapat menjadi obat yang sangat bermanfaat bagi kesehatan dan keselamatan bagi seseorang. Karena itu, musyawarah adalah upaya meraih madu itu di mana pun ia ditemukan, atau dengan kata lain, pendapat siapapun yang dinilai benar harus diambil tanpa mempertimbangkan siapa yang menyampaikannya.

Selanjutnya, al-Raghib mengartikan musyawarah dalam kamusnya dengan meminta satu sama lain untuk mengeluarkan pendapat secara berulang-ulang (AlAsfahani, 1992: 470). Jadi, istilah musyawarah pada dasarnya hanya digunakan untuk hal-hal yang baik, sejalan dengan makna dasarnya.

Sedangkan menurut istilah fiqh musyawarah berarti meminta pendapat orang lain atau umat mengenai suatu urusan. Kata musyawarah juga umum diartikan dengan perundingan atau tukar pikiran. Jadi, Perundingan itu juga disebut musyawarah, karena masing-masing orang yang berunding dimintai atau diharapkan mengeluarkan atau mengemukakan pendapatnya tentang suatu masalah yang dibicarakan dalam perundingan itu.

\subsection{Musyawarah dalam al-Qur`an}

Di dalam al-Qur'an, kata musyawarah (syura) dengan segala derivasinya disebutkan 4 kali, yaitu kata asyaarat (أشثارت) pada QS. Maryam: 29, kata tasyaawur (تشاور) pada QS. Al-Baqarah: 233, kata syaawirhum (شاور هم) dalam QS. 


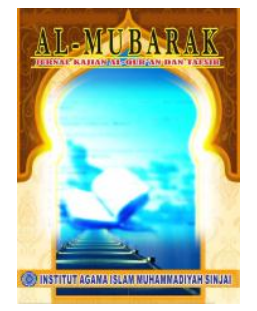

\section{Al-MUBARAK}

Jurmall Kajian Al-Quran \& Tafsir

Volume 4, No. 2, 2019

P-ISSN: 2548-7248

E-ISSN: 2715-5692

Homepage : http://journal.iaimsinjai.ac.id/indeks.php/al-mubarak

Ali Imran: 159 dan kata syura (نورى), pada QS. Al-Syura: 38 (Fuad Abdul Baqi, 2008: 391). Sedangkan kata yang menunjukkan tentang musyawarah hanya dikemukakan sebanyak tiga kali dalam tiga tempat yang berbeda dan dengan bentuk kata yang berbeda pula, yaitu kata tasyaawur (تشاور) pada QS. Al-Baqarah: 233, kata syaawirhum (شاور هم) dalam QS. Ali Imran: dan kata syura (شورى)159, pada QS. Al-Syura: 38. Ketiga ayat yang menjelaskan tentang musyawarah tersebut akan diuraikan sebagai berikut:

Terjemahnya:

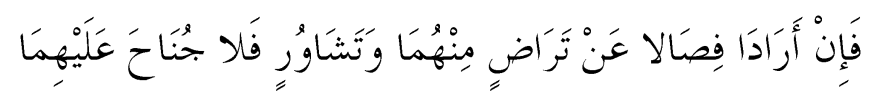

"Apabila keduanya (suami istri) ingin menyapih anak mereka (sebelum dua tahun) atas dasar kerelaan dan permusyawarahan antara mereka. Maka tidak ada dosa atas keduanya" (QS. Al-Baqarah/2: 233)

Ayat ini menjelaskan tentang musyawarah sebagai salah satu cara mengambil sebuah keputusan dalam rumah tangga, seperti keinginan seorang ibu atau bapak yang ingin menyapih anak mereka atau memisahkan anak dengan ibunya (tidak menyusuinya) sebelum dua tahun, maka kedua orang tuanya harus memusyawarahkan terlebih dahulu. Apakah mereka setuju untuk menyapih anak mereka atau tidak. Jika salah satu dari keduanya tidak menyetujuinya, maka menyapih anak mereka tidak boleh dilakukan. Dan jika tetap dilakukan meskipun tidak disetujui oleh keduanya, maka orang tua itu akan berdosa karena ini menyangkut kemaslahatan anak tersebut. Jadi pada ayat di atas, al-Qur'an memberi petunjuk agar setiap persoalan rumah tangga termasuk persoalan rumah tangga lainnya dimusyawarahkan antara suami isteri.

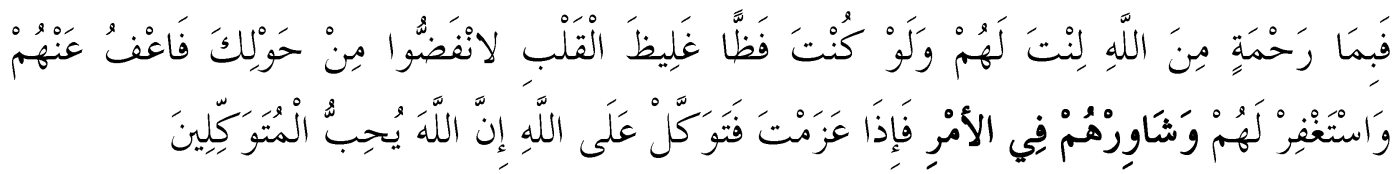

Terjemahnya:

"Maka disebabkan rahmat Allahlah, engkau bersikap lemah lembut terhadap mereka. Seandainya engkau bersikap kasar dan berhati keras. Niscaya mereka akan menjauhkan diri dari sekelilingmu. Kerena itu, maafkanlah mereka, mohonkanlah ampun bagi mereka, dan bermusyawarahlah dengan mereka dalam urusan tertentu. Kemudian apabila engkau telah membulatkan tekad, bertawakallah kepada Allah. Sesungguhnya Allah menyukai orangorang yang bertawakkal kepada-Nya”. (QS. Ali 'Imran/3: 159) 


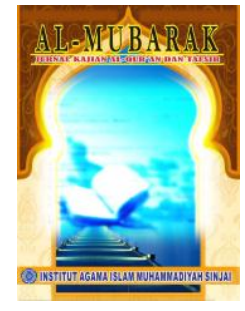

Al-MUBARAK

Jurmall Kajian Al-Quran \& Tafsir

Volume 4, No. 2, 2019

P-ISSN: 2548-7248

E-ISSN: 2715-5692

Homepage : http://journal.iaimsinjai.ac.id/indeks.php/al-mubarak

Teks ayat di atas berisi perintah kepada Nabi Saw. agar bermusyawarah dengan para sahabatnya, sebagaimana tercermin dalam klausa وَشََاورِهْْْ فِي الأمْرِ Bentuk perintah tersebut berbentuk tunggal sebagaimana dapat dipahami dari redaksi kalimat وَشَاوِرْْْهُ, artinya perintah tersebut hanya ditujukan kepada Nabi Saw. Namun para ahli tafsir menjelaskan bahwa meskipun perintah itu tunggal dan hanya ditujukan kepada Nabi, tapi perintah untuk melakukan musyawarah ditujukan kepada semua orang (Quraish Shihab, 1996: 475). Pandangan mereka ini sangat logis karena Nabi Saw. merupakan pemimpin ummat yang berkewajiban menyampaikan kandungan ayat kepada seluruh ummat manusia, termasuk musyawarah. Jika Nabi Saw. saja melakukan musyawarah dalam memutuskan suatu perkara, maka umatnya pun harus mengikutinya, terlebih lagi jika dipahami bahwa Nabi Saw. yang ma'sum saja masih melakukan musyawarah dalam memutuskan suatu perkara, apalagi umatnya yang jauh dari ke-ma'shuman.

Dalam konteks ini, kata syawir merupakan kata kunci yang akan dianalisis. Kata syaawir merupakan bentuk imperatif dari kata kerja syaawara-yusyaawiru yang mempunyai bentuk masdar dari kata musyaawarat. Makna pokok kata tersebut adalah menampakkan dan menawarkan sesuatu serta mengambilnya (Ibnu Faris: 226).

Pada mulanya, kata musyawarah bermakna mengeluarkan madu dari sarang lebah. Makna ini kemudian berkembang, sehingga mencakup segala sesuatu yang dapat diambil atau dikeluarkan dari yang lain (termasuk pendapat) (M.Quraish Shihab, 1996: 469). Dalam hal ini, al-Raghib mengartikannya dengan meminta pendapat satu sama lain dan mengeluarkannya secara berulang-ulang (Al-Raghib al-Asfahani: 470).

Selanjutnya, kata فِي الأمْرِ dalam redaksi ayat di atas berarti dalam urusan atau persoalan mereka. Urusan yang dimaksudkan dalam ayat ini adalah urusan dunia atau sosial kemasyarakatan. Bahkan ada ulama yang lebih memperluas makna al-amr bukan hanya urusan dunia, melainkan urusan agama juga, karena banyak persoalan agama yang muncul sekarang dan tidak terjadi pada masa Nabi Saw. atau masa lalu. Dalam hal ini, M Quraish Shihab mempertegas bahwa 


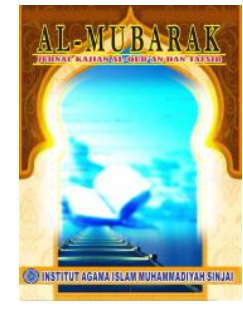

Volume 4, No. 2, 2019

P-ISSN: 2548-7248

E-ISSN: 2715-5692

Homepage : http://journal.iaimsinjai.ac.id/indeks.php/al-mubarak

musyawarah dapat dilakukan untuk segala masalah yang belum terdapat petunjuk agama secara jelas dan pasti, sekaligus yang berkaitan dengan kehidupan duniawi (M. Quraish Shihab, 1996: 479).

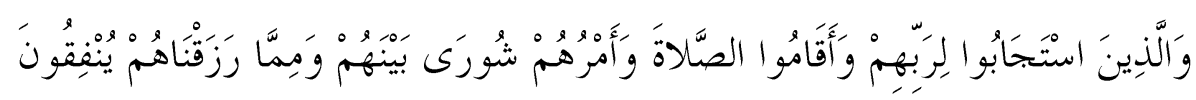

Terjemahnya:

"Dan (bagi) orang-orang yang menerima (mematuhi) seruan Tuhannya dan mendirikan shalat, sedang urusan mereka (diputuskan) dengan musyawarah antara mereka; dan mereka menafkahkan sebagian dari rezki yang Kami berikan kepada mereka." (QS. Asy-Syura: 38)

Ayat tersebut merupakan pujian kepada kelompok Muslimin Madinah (Anshar) yang bersedia membela Nabi Saw. dan menyepakatinya melalui musyawarah yang mereka lakukan di rumah Abu Ayyub al-Anshari (M. Quraish Shihab, 1996: 479).

Klausa ayat وَأَمْرُهُمْ شُورَى بَيْنَهُمْ menjelaskan bahwa mereka merundingkan urusan mereka tanpa terburu-buru, dan tidak mementingkan pandapat masingmasing dalam setiap masalah yang mendatangi mereka, yakni masalah yang menyangkut masyarakat luas seperti, pengangkatan khalifah, pengaturan negara, pengangkatan pemimpin wilayah, dan hukum-hukum peradilan. Demikian pula dengan urusan pribadi mereka, juga dirundingkan.

Ayat tersebut terdapat di dalan Surah Asy-Syura, yang artinya musyawarah. Hal tersebut membuktikan betapa pentingnya musyawarah dalam mengatasi setiap problema hidup yang dihadapi, khususnya persoalan yang menyangkut sosial kemasyarakatan.

Dalam beberapa ayat musyawarah yang dikutip sebelumnya, tidak dijelaskan tentang sifat-sifat yang harus dimiliki bagi mereka yang akan melakukan musyawarah. Namun, Nabi Saw menjelaskannya melalui hadisnya, sebagaimana diriwayatkan oleh Ali bin Abi Thalib.

\subsection{Prinsip-Prinsip Musyawarah dalam al-Qur`an}

Dalam QS. Ali 'Imran: 159 dijelaskan tentang adanya tiga sikap yang secara berurutan diperintahkan kepada Nabi Saw untuk dilaksanakan sebelum mengadakan musyawarah. Ketiga sikap tersebut harus dimiliki oleh orang yang 


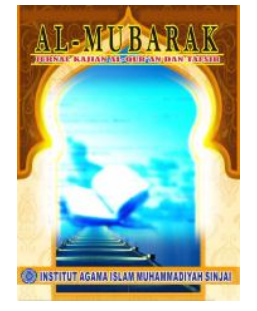

Al-MUBARAK

Jurnall Kajian Al-Quran \& Tafsir

Volume 4, No. 2, 2019

P-ISSN: 2548-7248

E-ISSN: 2715-5692

Homepage : http://journal.iaimsinjai.ac.id/indeks.php/al-mubarak

akan ikut dalam musyawarah agar pelaksanaannya dapat berjalan sesuai dengan harapan. Sikap dasar tersebut dapat dlihat dalam QS. Ali 'Imran: 159, yaitu:

\section{a. Sikap Lemah Lembut dan Tidak Ekstrim}

Bagi setiap peserta dalam musyawarah, hendaknya memiliki sikap lemah lembut dan sedapat mungkin menghindari kata-kata yang kasar dan dapat menyinggung peserta musyawarah yang lain, tidak ekstrim dan tidak keras kepala. Jika sikap ini tidak dijaga dan tidak dipraktekkan dalam musyawarah, maka peserta musyawarah yang lain dapat meninggalkan musyawarah yang sedang berlangsung. Bahkan musyawarah tersebut dapat menimbulkan pertikaian dan pertentangan, sehingga tujuan musyawarah agar dapat melahirkan ide-ide cemerlang atau pendapat yang baik dan mulia tidak dapat tercapai. Sikap lemah lembut ini dapat dipahami dari klausa ayat:

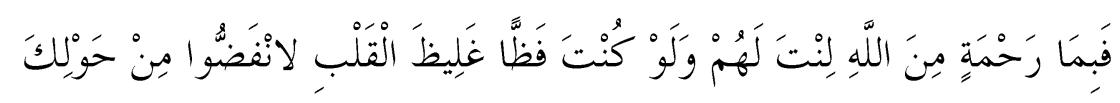

Menurut Muhammad Abduh sebagaimana dijelaskan oleh muridnya Muhammad Rasyid Ridha bahwa ayat di atas turun berkenaan dengan sebuah peperangan yang di dalamnya terjadi perbedaan pendapat antara Nabi Saw dengan sebagian sahabat sehingga mengakibatkan lemahnya semangat sebagian dari mereka dan di saat yang sama, kaum musyrikin muncul, sehingga Nabi Saw dan para sahabatnya mengalami kekalahan dalam perang tersebut, yaitu perang Uhud. Namun, Nabi Saw tetap bersikap lemah lembut dalam mempergauli mereka (Muhammad Rasyid Ridha, t.th.: 198).

Menjelang perang Uhud, Nabi Saw mengumpulkan para sahabatnya untuk memusyawarahkan cara atau strategi menghadapi musuh yang sedang bergerak dari Makkah menuju Madinah. Dalam musyawarah tersebut, ada dua strategi yang dapat dipilih untuk mengahadapi musuh, yaitu ofensif dan defensif. Secara pribadi, Nabi Saw memilih defensif dan tetap bertahan di kota Madinah. Akan tetapi, para sahabatnya, utamanya dari kaum muda mendesak agar kaum muslimin di bawah pimpinan Nabi Saw agar keluar menyongsong musuh. Pendapat ini mendapat dukungan mayoritas, sehingga Nabi Saw menyetujuinya. Dalam perang tersebut, kaum muslimin mengalami kekalahan dan tidak kurang dari tujuh puluh 


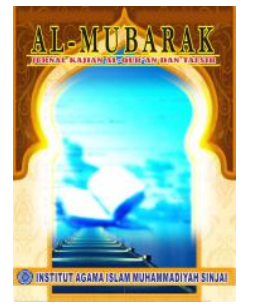

Al-MUBARAK

Jurnall Kajian Al-Quran \& Tafsir

Volume 4, No. 2, 2019

P-ISSN: 2548-7248

E-ISSN: 2715-5692

Homepage : http://journal.iaimsinjai.ac.id/indeks.php/al-mubarak

orang dari sahabat Nabi Saw gugur di medan pertempuran (AI-Surur, 1977: 475476).

\section{b. Sikap Lapang Dada, Terbuka, dan Pemaaf}

Sikap ini harus dimiliki oleh mereka yang ikut bermusyawarah karena dalam bermusyawarah sering kali terjadi perbedaan pendapat, bahkan perselisihan dan pertengkaran di antara mereka. Dengan adanya sikap ini, perselisihan dan pertengkaran dapat diredam. Sikap lapang dada, toleran dan memaafkan satu sama lain akan melahirkan pikiran yang jernih, sehingga dapat mengambil salah satu pendapat yang paling baik di antara mereka. Klausa ayat فَاعْفُ عَنْهُ pada QS. Ali 'Imran: 159 merupakan landasan dan petunjuk bahwa memberi maaf kepada mereka yang telah mengeluarkan kata-kata kasar dan pernyataan yang dapat menyinggung perasaan dalam bermusyawarah merupakan sikap yang harus dimiliki dan diamalkan.

\section{c. Rendah Hati dan Memohon Ampun}

Sikap ini dapat dipahami dari klausa ayat وَاسْتَغْفْرْ لَهُمْ dalam QS. Ali 'Imran: 159. Klausa ayat ini memerintahkan untuk memohonkan ampun bagi mereka kepada Allah Swt, atas hal-hal yang berkaitan dengan hak-Nya, agar curahan kasih sayang dan pemeliharaan-Nya dapat terwujud secara maksimal (Al-Alusy, 1993: 166).

\section{d. Sikap Kebulatan Tekad dan Tawakkal}

Sikap ini dilakukan setelah musyawarah dilaksanakan dan telah menghasilkan suatu keputusan. Sikap ini tergambar dalam klausa ayat فَذِاذَا عَزَمْتَ

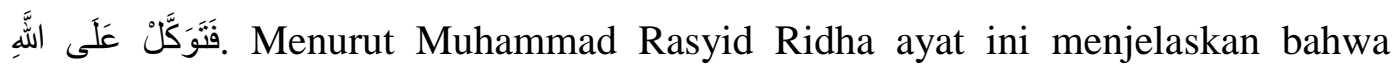
apabila musyawarah telah dilaksanakan dan telah menghasilkan sebuah keputusan yang telah dipilih oleh forum, maka seluruh peserta musyawarah harus berketetapan hati untuk menjalankannya, kemudian bertawakkal kepada Allah Swt. (Muhammad Rasyid Ridha: 205). Keputusan tersebut harus dilaksanakan dengan sepenuh hati, meskipun keputusan tersebut berbeda dengan pendapat sebagian dari peserta musyawarah. 


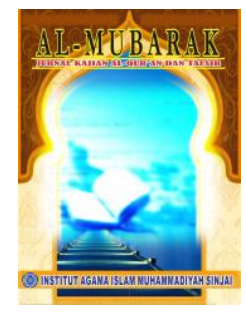

Al-MUBARAK

Jurmall Kajian Al-Quran \& Tafsir

Volume 4, No. 2, 2019

P-ISSN: 2548-7248

E-ISSN: 2715-5692

Homepage : http://journal.iaimsinjai.ac.id/indeks.php/al-mubarak

\section{Simpulan}

Musyawarah merupakan sebuah forum untuk mengemukakan pendapat dalam menyelesaikan suatu masalah. Pendapat-pendapat yang dikemukakan oleh peserta musyawarah tersebut, dipilih salah satu pendapat yang paling tepat, tanpa melihat siapa yang mengemukakan pendapat tersebut. Al-Qur'an tidak menentukan bentuk atau pola musyawarah tertentu. Bentuk musyawarah tersebut disesuaikan dengan budaya dan kondisi suatu masyarakat. Al-Qur'an hanya memerintahkan dan menjelaskan prinsip-prinsipnya. Prinsip-prinsip atau sikap yang harus dimiliki oleh peserta musyawarah menurut al-Qur'an adalah sikap lemah lembut dan tidak ekstrim; lapang dada, terbuka dan pemaaf; rendah hati dan memohon ampun; dan sikap kebulatan tekad dan tawakkal.

\section{Daftar Pustaka}

Abdul Baqi, Muhammad Fu'ad. (2008). Mu'jam al-Mufahras Li Alfazh al-Qur'an al-Karim. (Kairo: Dar al-Kitab al-Mishriyyah.

Ahmad Syalabi. (1978). Mawsu'at al-Tarikh al-Islamiy. Kairo: Maktabat alNahdat.

Al-'Alusiy al-Baghdadiy, Abi al-Fadhl Syihaab al-Diin al-Sayyid Mahmuud. (1993). Ruh al-Ma'aniy fii Tafsiir al-Qur'an al-'Azhiim wa al -Sab alMasani. Beirut: Dar al-Fikr.

Al-Asfahaniy, Al-Raghib. (1992). Mu'jam Mufradat Li Alfazh al-Qur'an . Damaskus: Dar al-Qalam.

Al-Buthy, Muhammad Sa'id Ramadhan. (1980). Fiqh al-Sirah. Bairut: Dar alFikr.

Ibn Hisyam. (1955). Al-Sirah al-Nabawiyyah. Mesir: Mushthafa al-Babiy alHalabiy.

Al-Khurbutuliy, 'Aliy Husniy. (T.Th.). Al-Rasul Saw fi al-Madinah. Mesir: Majlis A'ala li Su'un al-Islamiyyah.

Ibn Manzhur. (2008). Lisan al-Arab. Beirut: Dar al-Maarif.

Ibn Zakariya, Abu al-Husain Ahmad bin Faris. (T.Th.). Mu'jam Maqayis alLughah. Beirut: Dar al-Fikr. 


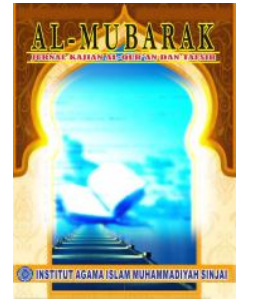

\section{Al-MUBARAK}

Jurmal Kajian Al-Quran \& Tafsir

Volume 4, No. 2, 2019

P-ISSN: 2548-7248

E-ISSN: 2715-5692

Homepage : http://journal.iaimsinjai.ac.id/indeks.php/al-mubarak

Ridha, Muhammad Rasyid. (T.Th.). Tafsir al-Qur'an al-Hakim. Beirut: Dar alFikr.

Shihab, M. Quraish. (1996). Wawasan al-Qur'an: Tafsir Maudhu' atas Pelbagai Persoalan Ummat. Bandung: Mizan.

Al-Surur, Muhammad Jamal al-Din. (1977). Qiyaam al-Daulah al-'Arabiyyah alIslamiyyah Muhammad Saw. Kairo: Dar al-Fikr al-'Arabiy.

Syaraf, Muhammad Jalal dan 'Aliy al-Mu'thiy Muhammad. (1998). Al-Fikr alSiyasiy fi al-Islamiy: Syakhshiyat wa al-Madzahib. Beirut: Dar al-Fikr.

Syarif, Ahmad Ibrahim. (1965). Al-Daulah al-Islamiyyah al-Ula. ttp: Dar alQalam.

Al-Thabariy, Abu Ja'far Muhammad ibn Jarir. (1979). Tarikh al-Umam wa alMuluk. Beirut: Dar al-Fikr. 